\title{
Identifying the Employment Needs of People With Chronic Health Conditions in Europe
}

\author{
Carolina C. Ávila, PhD, Jose Luis Ayuso-Mateos, MD, PhD, Amalia Muñoz-Murillo, MSc, \\ Chiara Scaratti, PsyD, Michaela Coenen, MHP, PhD, Anastasia Vlachou, PhD, Klemens Fheodoroff, MD, \\ Aleksandra Pilat, MA, Aleksandra Tabaj, PhD, Olga Svestkova, MD, PhD, Asel Kadyrbaeva, MSc, \\ and Maria Cabello, PhD
}

\begin{abstract}
Objectives: The main goal of this study was to compare the employment needs experienced by people with different chronic health conditions and in different welfare systems. Methods: A total of 688 participants with six chronic health conditions were collected in nine countries representing four welfare systems in Europe (Continental, Mediterranean, Postcommunist, and Scandinavian). Results: Raising awareness of what is to live with a chronic health condition in the workplace was the area perceived as more favorable. The types of employment needs were different across the social welfare systems but did not vary among the different chronic health conditions groups. Conclusion: Although diverse, there appear to be some common needs transversal to the working experience of people with chronic health problems. Actions to improve the employability of people with chronic health conditions should be tailored to each welfare system.
\end{abstract}

From the Department of Psychiatry, Universidad Autonoma de Madrid, Madrid, Spain (Dr Ávila, Dr Ayuso-Mateos, and Dr Cabello); Instituto de Salud Carlos III, Centro de Investigación Biomédica en Red de Salud Mental (CIBERSAM), Madrid, Spain (Dr Ávila, Dr Ayuso-Mateos, Dr Cabello); Instituto de Investigación Sanitaria Princesa (IIS-Princesa), Madrid, Spain (Dr Ávila, Dr Ayuso-Mateos, Dr Cabello); Research Unit, Parc Sanitari Sant Joan de Déu, Universitat de Barcelona, Sant Boi de Llobregat, Spain (Ms Muñoz-Murillo); Department of Neurology, Public Health and Disability Unit, Neurologica Institute "C. Besta" IRCCS, Foundation, Milan, Italy (Dr Scaratti); Institute for Medical Information Processing, Biometry and Epidemiology - IBE, Chair for Public Health and Health Services Research, Research Unit for Biopsychosocial Health, Ludwig-Maximilians-Universität, Munich, Germany (Dr Coenen); Department of Special Education, University of Thessaly, Volos, Greece (Dr Vlachou); Neurorehabilitation, KABEG Gailtal-Klinik, Hermagor, Austria (Dr Fheodoroff); Department of Medica Sociology, Chair of Epidemiology and Preventive Medicine, Jagiellonian University Medical College, Krakow, Poland (Ms Pilat); Development Unit for Employment Rehabilitation, University Rehabilitation Institute Republic of Slovenia, Ljubljana, Slovenia (Dr Tabaj); Department of Rehabilitation Medicine. Faculty of Medicine Charles University, Prague, Czech Republic (Dr Svestkova); European Association of Service providers for Persons with Disabilities, Brussels, Belgium (Ms Kadyrbaeva).

Authors' contribution: CCA wrote the first draft of the manuscript; AMM, CS, $\mathrm{MCo}, \mathrm{AV}, \mathrm{KF}, \mathrm{AP}, \mathrm{AT}$, and OS participated in the design of the questionnaire and coordinated data collection at national level. AK and JLAM searched patient's associations and made contributions in the selection of the study variables. Finally, MCa performed the statistical analyses, conceived the objectives, and coordinated the whole process. All the authors made substantial contributions and approved the final version of the manuscript.

This study received funding from the European Union's Health Programme (2014 to 2020) Grant agreement n. 663474. The funding source had not any involvement either in the study design or in the interpretation of results.

Clinical significance: There is a shared experience of employment needs across different chronic health condition groups that might be managed by one common intervention. Actions aimed at increasing the participation of chronic health conditions in the workforce should be tailored to each country's welfare system characteristics.

The authors report no conflicts of interest.

Supplemental digital contents are available for this article. Direct URL citation appears in the printed text and is provided in the HTML and PDF versions of this article on the journal's Web site (www.joem.org).

Address correspondence to: Maria Cabello, PhD, Arzobispo Morcillo 4, 28029, Madrid, Spain (maria.cabello@uam.es).

Copyright (C) 2018 American College of Occupational and Environmental Medicine

DOI: 10.1097/JOM.0000000000001425
Keywords: Chronic diseases, Employment needs, Survey, Welfare

A ccording to the World Health Organization (WHO), "noncommunicable diseases" (NCDs), also known as chronic diseases, are not passed from person to person. They are of long duration and generally slow progression. ${ }^{1}$ As the global population is aging, chronic health conditions are more and more prevalent worldwide. $^{2}$

People with chronic health problems are frequently unemployed. ${ }^{3}$ There are probably multiple reasons that account for this: people with chronic health conditions have frequently poorer quality jobs, ${ }^{3}$ are more likely to lose their jobs, ${ }^{4}$ and have less probabilities to be (re)integrated into the workforce. ${ }^{5}$ Unemployment make people with chronic health problems more vulnerable to poverty ${ }^{6}$ and to mental health problems. ${ }^{3}$ On the contrary, people with health problems who transitioned from receiving disability benefits to be actively working, reported higher mental and physical health than those who remained in disability benefits. ${ }^{7}$

Scientific literature reporting information on employment needs in people with chronic health conditions has some limitations. First, existing literature has mainly focused on specific needs such as physical adaptations, ${ }^{8}$ working conditions, ${ }^{9}$ or factors associated with return to work, ${ }^{10}$ whereas complete lists of needs have been less reported. Second, some of the existing studies that provide more extensive employment needs information are focused on specific health conditions groups, ${ }^{11-13}$ which does not help to understand the common needs that people with chronic health conditions might share. Third, the existing studies including people with several chronic health conditions and extensive list of needs have only collected data from onecountry, ${ }^{14,15}$ so the applicability of their results is probably restricted to their population and country characteristics. Finally, no study to our knowledge has analyzed whether the type of occupation and the extension of the country social benefits might have an impact on people's work needs.

Authors generally agree that there are five types of welfare systems in Europe: Scandinavian, Continental, Anglo-Saxon, Mediterranean, and Postcommunist. ${ }^{16,17}$ In summary, the Scandinavian model, which is developed in countries such as Norway, Finland, Denmark, and Sweden, is defined by high levels of social protection and universal health services that are supported by high tax rates. ${ }^{18}$ Scandinavian model promotes active employment policies since people with health problems receive wide social benefits that are made conditional to complete vocational and training programs. ${ }^{16}$ Therefore, this model promotes people's capabilities and prepares them for paid employment. ${ }^{16}$ As a result, the participation of people with health problems in the open labor market is generally high. ${ }^{18}$ On the contrary, the Continental model (Germany, France, Austria, Belgium, and Croatia) places emphasis on wide social protection (although less extensive than Scandinavian model) and the existence of population health services that are covered by employers and employees. ${ }^{19}$ The work strategies for people with health problems are mainly passive since people who receive social benefits have few incentives and even sometimes restrictions to participate in the open 
labor market. ${ }^{16}$ Sheltered work and part-time employment are the most frequent employment options for people with health problems in these countries. ${ }^{20}$ The Anglo-Saxon model is implemented in United Kingdom and Ireland. This model, called also "liberal", is characterized by low public social assistance, allocating most of the social funds to working population sector. ${ }^{17}$ Active labor policies are developed so that people with health problems participate in the open labor market, ${ }^{16}$ which is characterized by high flexibility and wage dispersion. ${ }^{17}$ People with health problems and unemployed are at higher risk for poverty and underpayment. ${ }^{16}$ The Mediterranean model, which is located in Greece, Portugal, Italy, and Spain, has been described as a fragmented welfare system that overprotects certain population groups (particularly those who reached a certain disability threshold) while under protecting other population sectors. ${ }^{19}$ Mediterranean model has less generous social provisions in comparison with continental model. ${ }^{20}$ Family, charitable organizations and informal support become important agents to cover the existing social needs. ${ }^{19}$ Employment policies are characterized by providing partial and low-wage social benefits to people with health problems with no incentives to participate in the work market. Poverty rate among people with health problems is generally high. ${ }^{21}$ Finally, Postcommunist model has been defined as ongoing transition model coming from a collectivist vision to a neoliberal system. ${ }^{22}$ Postcommunist welfare system is characterized by low social spending and poor health service coverage. ${ }^{19}$ Countries with a Postcommunist welfare generally lack of coherent employment policies, services, and systems for people with health problems. ${ }^{20}$ Postcommunist welfare system is located in countries such as Slovenia, Czech Republic, Poland, Slovakia and Estonia among others. To our knowledge no previous studies have analyzed whether people with chronic health conditions have different employment needs depending on the type of welfare system they benefit from.

This study is part of an European project which is aimed to systematically collect what has been done in terms of existing employment strategies, what is scientifically effective and what is perceived as needed so that people with chronic health conditions can fully participate at the work market. ${ }^{23}$ The present study is aimed to gather directly the perspective of people with chronic health conditions on what factors they perceived as favorable or unfavorable to their full participation and performance in the work market as well to compare whether the type of employment needs vary according to the type of chronic health condition experienced to the type of social welfare system and to type of occupation.

\section{METHODS}

\section{Design}

Employment needs were, for the purpose of the project, defined according to the framework of the International Classification of Functioning, Disability and Health (ICF), ${ }^{24}$ as the modifiable environmental and/or personal factors that hinder (barriers) or/and facilitate (facilitators) people with chronic health conditions to participate in the labor force and to perform work activities in a similar way as people without chronic conditions.

The project targeted 6 "umbrella chronic conditions groups", representing the leading causes of Years Lived with Disability in Europe in 2015 (i.e. musculoskeletal disorders; mental and substance use; neurological disorders; diabetes, urological, blood and Endocrine disorders; Cardiovascular diseases and Chronic respiratory). ${ }^{25}$ From these 6 main health conditions groups, one/two specific health conditions were selected because of their high prevalence in the workplace and/or due to the expertise of the participating centers. These specific health conditions are showed in the supplementary material (Table A), http://links.lww.com/JOM/ A473.
A step-by-step methodology was developed to firstly design an instrument able to collect the relevant employment needs, to secondly implement the questionnaire across the nine participating countries and, finally, to analyze the results obtained.

\section{Designing of a Questionnaire to Collect the Employment Needs}

First, different systematic mappings of the literature were conducted (one for each chronic health condition) to obtain a list of potential needs that were preidentified in previous studies and serve as starting point. The WHO's International Classification of Diseases version 10th codes (ICD-10) ${ }^{26}$ were used to operationalize the specific health conditions selected in literature (see supplementary tables, http://links.lww.com/JOM/A473). All the mappings followed the same general inclusion criteria (ie, studies including samples of the above mentioned chronic health conditions and reporting employment needs). Electronic searching included sensitive keywords for each health condition and common words for employment needs. Pubmed and PsycInfo were the databases consulted. A secondary manual search including gray literature (reports, books, memories) was also performed for certain health conditions in case the number of articles found was lower than five. Employment needs and other study characteristics (sample size, design, country, and specific health condition/s collected) were extracted for all the articles and aggregated into one common database. Duplicate needs across health conditions were eliminated and similar or related needs were consolidated.

Second, a set of employment needs questions was designed based on the information extracted from the systematic mappings of the literature. All the questions were formulated so that participants had to rank to what extent a particular need was relevant for them. A 5-point scale was used to rate the interest of each possibility or strategy proposed to facilitate employment, ranging from "very unfavorable", to "very favorable." 5 The list of employment needs questions is included in the supplementary table B, http://links.lww.com/JOM/A473. Additionally to the employment need questions, the study protocol included information on basic demographics such as age (in years), sex, living situation (living with own family; living with family of origin; living alone; living in a shared apartment; living in a residence of facility), occupational situation (employed for pay; not employed for pay), employment situation (working under a mainstream contract, working under special regimen or at sheltered employment, independent worker or entrepreneur without benefits for health condition, independent worker or entrepreneur with benefits for health condition), and current occupation, which was collected into 10 different categories according to the International Standard Classification of Occupations (ISCO) (Managers, Professional, Technicians and associate professionals, Clerical support workers, Service and sales workers, Skilled agricultural, forestry and fishery workers, Craft and related trades workers, Plant and machine operators, and assemblers, Elementary occupations, and Armed forces occupations). ${ }^{27}$ As people with chronic conditions usually experience more than one health condition, participants were asked to provide their answers taking into consideration the health condition they identified as primary. Moreover, information on other comorbid chronic conditions and other known medical or psychological conditions, genetic syndromes, allergies, or intolerances was also collected.

Type of welfare system was also included. The project collected participants from four different welfare systems in Europe: Continental (people living in Germany, Austria, and Slovenia), Mediterranean (participants from Greece, Italy, and Spain), Nordic/Scandinavian (Norway), and Postcommunist (Czech Republic and Poland). ${ }^{20}$ 


\section{Implementation of an Online Survey in Nine European Countries}

All the study questions were originally created in English and translated into their respective national languages by the project researchers (Czech, Italian, German, Greek, Norwegian, Polish, Slovene, and Spanish). Each of the nine recruiting countries (Austria, Czech Republic, Germany, Greece, Italy, Norway, Poland, Slovenia, and Spain) established different Google Forms platforms for their corresponding national language. The first page of the online survey informed participants about scope, content, and the kind of information collected. A national contact was available in all the online forms in case of questions or further information. The submission of answers implied the consent of people to participate. The study was locally approved by the Ethics Committees of the following institutions: Gailtal Klinik-Neurologische Rehabiliation (Austria), Ludwig-Maximilians-Universitataet Muenchen (Germany), PanepistimioThessalias (Greece), Fondazione IRCSS IstitutoNeurologico Carlo Besta (Italy), Uniwesrytet Jagiellonski (Poland), University Rehabilitation Institute (Slovenia), ParcSanitari Sant Joan de Déu (Spain), and Universidad Autónoma de Madrid (Spain). Following the local rules, data collected from Czech Republic and Norway did not require local ethical approvals because the study had already been approved by the study coordinator. Helsinki declaration principles of anonymity and confidentiality were met in all the cases.

\section{Sample}

The study inclusion criteria were adults (18 to 66 years old), who had been diagnosed of any of the six chronic health conditions above mentioned. A two-stage sampling process was used. First, the researchers identified a list of relevant organizations (eg, NGOs, patients associations) for each participating country. In total, 91 national and regional organizations were identified. A responsible person from each organization was contacted by mail so that they could disseminate the questionnaire among the people with the selected chronic health conditions. The email included the link to participate in the survey, a summary of the study objectives along with the request to contact members of the patient organizations and to inform them about the survey. A total of $55(60 \%)$ organizations answered and agreed to distribute the study by means of their usual disseminating procedures (newsletter, information published on websites, contact via e-mail). Final sample were those patients who met the inclusion criteria and were interested to participate in the online survey. Data collection was conducted between August and October 2016.

\section{Statistical Analyses}

Two types of statistical analyses were conducted. One of them was addressed to check the properties of the questionnaire. The second ones were aimed to describe and compare the employment needs across the different chronic health condition groups.

First, one confirmatory factor analysis (CFA) was run using the Weight Least Square Mean (WLSM) estimation to check whether latent structure of the scale fitted with a six-factor model (ad hoc hypothesized). The fit of the model was assessed considering the Comparative Fit Index (CFI), the Tucker-Lewis Index (TLI), and the Root Mean Square Error of Approximation (RMSEA). Standards proposed by $\mathrm{Hu}$ and Bentler (1999) were considered as indicators of an acceptable fit: CFI $>0.90$; TLI $>0.90$; RMSEA $<0.08$. The reliability of the six different employment domains was also estimated using the Cronbach's alpha coefficients. Interpretation of Cronbach's alpha was done according to Cohen's recommendations. ${ }^{28}$

Secondly, a general profile comprising sociodemographic, health and the specific employment needs characteristics of the sample was obtained. Mean and standard deviation (SD) for continuous variables and frequencies and percentages for qualitative ones were calculated. Items were added into their respective employment need domain to obtain six different employment domain scores. As each employment domain included different number of items, raw total scores were transformed them into a 0 to 100 range so that the six domains scores were comparable. Higher scores meant the domain was perceived as more favorable. Chisquared tests for qualitative variables and ANOVA for quantitative variables were conducted to check differences in demographic, health characteristics and employment needs domains across the six main health condition groups (Depression, Ischemic Heart Disease, Diabetes, Chronic Obstructive Pulmonary disease, Migraine and Low \& Back Pain). In addition, ANOVA analyses were run to see whether the employment need domains were differently perceived across the four welfare system groups (Nordic, Continental, Mediterranean, and Eastern). Effect sizes (Cohen's d and Cramer's V for quantitative and qualitative variables, respectively) and Post-hoc Bonferroni comparisons were calculated in case the results of the group comparisons were significant. Statistical significance was considered with a $P$ value $\leq 0.05$. Missing cases were not imputed. All the statistical analyses were conducted with STATA version $14^{29}$ and Mplus version $7 .^{30}$

\section{RESULTS}

\section{Designing of a Questionnaire to Collect the Employment Needs}

PubMed and PsychInfo databases revealed 1249 unique publications (12 for migraine search terms, 232 for depression, 249 for COPD, 125 for back and neck pain, 325 for diabetes; and 306 for ischemic heart disease) for the 5 previous years. After applying exclusion and inclusion criteria by two independent researchers, a total of 122 articles were included in the mapping (3 for migraine, 26 for depression, 71 for COPD, 14 for Back and neck pain, 5 for diabetes, 3 for ischemic heart disease) and the needs mentioned in those articles were extracted and computed for inclusion in the survey questionnaire.

A total of 40 needs aggregated into 6 different categories were identified and selected in order to cover the whole spectrum of the 6 chronic health conditions and address both employed as unemployed participants.

The six domains were named as follows: (1) Environmental and Physical adaptations of the workplace; (2) Working Conditions; (3) Legislative needs; (4) Medical and Health Care needs; (5) Personal Education and Training; and (6) Raising Awareness in the Workplace. This six-factor model adjusted properly $(\mathrm{RMSEA}=0.05 ; \mathrm{TFI}=0.92 ; \mathrm{CFI} ; 0.93)$. The specific factor loadings (Supplementary table B, http://links.lww.com/JOM/ A473) ranged from 0.36 to 0.81 indicating a significant contribution of all the items on their corresponding domains. Only item 15 from domain "working conditions" and item 24 from "legislative needs" domain obtained factors lower than 0.05 . These two items were not considered in the respective employment domain scoring. The Cronbach alpha coefficients of the six domains ranged from 0.79 to 0.84 indicating a moderate-to-high internal consistence.

\section{Implementation of an Online Survey in Nine European Countries}

\section{Basic Characteristics of the Sample}

A total of 857 participants completed the survey. After excluding participants who did not have as main chronic health condition one of the 6 selected diagnoses, answers from 686 
TABLE 1. Main Demographic Data For Total Sample and by Type of Health Condition

\begin{tabular}{|c|c|c|c|c|c|c|c|c|c|}
\hline Variables & $\begin{array}{c}\text { Total } \\
\text { Sample } \\
(n=686)\end{array}$ & $\begin{array}{l}\text { Migraine } \\
(n=137)\end{array}$ & $\begin{array}{c}\text { Back and } \\
\text { Neck Pain } \\
(\boldsymbol{n}=95)\end{array}$ & $\begin{array}{c}\text { COPD } \\
(n=86)\end{array}$ & $\begin{array}{l}\text { Depression } \\
(n=122)\end{array}$ & $\begin{array}{l}\text { Diabetes } \\
\text { Mellitus } \\
(n=191)\end{array}$ & $\begin{array}{c}\text { Ischemic } \\
\text { Heart Disease } \\
\quad(n=55)\end{array}$ & $\begin{array}{c}\chi^{2} / F^{*} \\
(P)\end{array}$ & $\mathbf{E} \mathbf{S}^{\dagger}$ \\
\hline Sex: females $n, \%$ & $470(68.81)$ & $122(89.71)$ & $73(76.84)$ & $46(54.12)$ & $89(73.55)$ & $120(62.83)$ & $20(36.36)$ & $70.51(P<0.001)$ & 0.32 \\
\hline Age: mean (SD) & $45.39(0.44)$ & $43.18(0.87)$ & $45.91(1.13)$ & $49.41(1.32)$ & $43.57(1.01)$ & $44.35(0.86)$ & $51.41(1.24)$ & $7.57(P<0.001)$ & 0.22 \\
\hline $\begin{array}{l}\text { Paid employment: } \\
\text { yes } n, \%\end{array}$ & $467(68.08)$ & $100(72.99)$ & 55 (57.89) & $54(62.79)$ & $71(58.20)$ & $150(78.53)$ & $37(67.27)$ & $4.56(P<0.001)$ & 0.16 \\
\hline $\begin{array}{l}\text { Employment situation } \\
\text { (only employed) } n, \%\end{array}$ & & & & & & & & $26.46(P=0.055)$ & 0.13 \\
\hline $\begin{array}{l}\text { Mainstream } \\
\text { employed }\end{array}$ & $386(79.42)$ & $90(85.71)$ & $48(80)$ & $42(70)$ & $58(79.45)$ & $120(80.54)$ & $28(71.79)$ & & \\
\hline $\begin{array}{l}\text { Quota/shelter/other } \\
\text { special }\end{array}$ & $44(9.05)$ & $7(6.67)$ & $4(6.67)$ & $5(8.33)$ & $7(9.59)$ & $16(10.74)$ & $5(12.82)$ & & \\
\hline $\begin{array}{l}\text { Mainstream } \\
\text { self-employed }\end{array}$ & $42(8.64)$ & $3(2.86)$ & $7(11.67)$ & $11(18.33)$ & $5(6.85)$ & $13(8.72)$ & $3(7.69)$ & & \\
\hline $\begin{array}{l}\text { Special regimen } \\
\text { self-employed }\end{array}$ & $14(2.88)$ & $5(4.76)$ & $1(1.67)$ & $2(3.33)$ & $3(4.11)$ & 0 & $3(7.69)$ & & \\
\hline Education, $n \%$ & & & & & & & & $45.49(P<0.001)$ & 0.15 \\
\hline $\begin{array}{l}\text { Secondary } \\
\text { education or less }\end{array}$ & 133 (19.39) & $21(15.33)$ & $24(25.26)$ & $31(36.05)$ & $23(18.85)$ & 21 (10.99) & $13(23.64)$ & & \\
\hline $\begin{array}{l}\text { High school/ } \\
\text { professional } \\
\text { diploma }\end{array}$ & 274 (39.94) & $44(32.12)$ & $46(48.42)$ & $25(29.07)$ & $51(41.80)$ & $85(44.50)$ & $23(41.82)$ & & \\
\hline Bachelor degree & $114(16.62)$ & $28(20.44)$ & $14(14.74)$ & $11(12.79)$ & $22(18.03)$ & $30(15.71)$ & $9(16.36)$ & & \\
\hline $\begin{array}{l}\text { University } \\
\text { completed }\end{array}$ & $165(24.05)$ & $44(32.12)$ & $11(11.58)$ & $19(22.09)$ & $26(21.31)$ & $55(28.80)$ & $10(18.18)$ & & \\
\hline Income perception, $n \%$ & & & & & & & & $7.37(P=0.69)$ & \\
\hline $\begin{array}{l}\text { I earn the same } \\
\text { than others }\end{array}$ & $292(42.88)$ & $48(35.29)$ & $37(39.78)$ & 35 (41.67) & 39 (31.97) & $105(54.97)$ & $28(50.91)$ & & \\
\hline $\begin{array}{l}\text { I earn less than } \\
\text { people with my } \\
\text { educational level/ } \\
\text { profession }\end{array}$ & $355(52.13)$ & $81(59.56)$ & $53(56.99)$ & $43(51.19)$ & $79(64.75)$ & $75(39.27)$ & $24(43.64)$ & & \\
\hline $\begin{array}{l}\text { I earn more than } \\
\text { others }\end{array}$ & $34(4.99)$ & $7(5.15)$ & $3(3.23)$ & $6(7.14)$ & $4(3.28)$ & $11(5.76)$ & $3(5.45)$ & & \\
\hline Comorbid problems, $n \%$ & & & & & & & & $69.94(P<0.001)$ & 0.23 \\
\hline None & $122(17.78)$ & $16(11.68)$ & $15(15.79)$ & $9(10.47)$ & $8(6.56)$ & $65(34.04)$ & $9(16.36)$ & & \\
\hline Two & $302(44.02)$ & $61(44.53)$ & $29(30.53)$ & $45(52.53)$ & $62(50.82)$ & $72(37.70)$ & $33(60.00)$ & & \\
\hline More than two & 262 (38.19) & $60(43.80)$ & $51(53.68)$ & $32(37.21)$ & $52(42.62)$ & $54(28.27)$ & $13(23.64)$ & & \\
\hline
\end{tabular}

$(80.04 \%)$ participants were analyzed. From these, $69 \%$ (70\%) were female, and mean age was 45 years (SD 0.44). Table 1 shows the main characteristics of the study population. More than $80 \%$ of the participants $(n=564)$ reported to have at least a secondary comorbid health condition. There were significant differences across health conditions in the variables: sex, age, level of education, employment situation and presence of comorbid problems. However, sizes effects of these differences were moderate to small.

\section{Description of the Specific Employment Needs}

Descriptive analyses of the 40 items showed that more than half of the items were rated "very favorable" to at least $50 \%$ of the participants (Supplemental material, http://links.lww.com/JOM/ A473). The items more frequently rated as favorable were those related to Working conditions, that is, "Having the possibility to secure time-off for medical appointments" considered as favorable or very favorable by $90 \%$ of participants, and "Having a flexible work routine with the possibility to manage timings in an independent way and to adjust breaks and schedules" which was considered as favorable or very favorable by $87 \%$ of participants $(n=562)$. On the contrary, "Giving the company the possibility lo legally terminate the job in case productivity decreases due to chronic condition" was rated as unfavorable/very unfavorable by $75 \% \quad(n=468)$ of participants.

\section{Employment Needs Categories by Chronic Health Conditions Groups}

Mean scores for each employment need domain by the different health condition groups and in the total sample are showed in Table 2. The employment need domain with higher scores (rated more frequently as favorable) was raising awareness in the workplace, whereas the domains with lower scores (rated less frequently as favorable) were specific medical and health care and legislative actions. All the employment domain mean scores were considered similarly favorable across the different health condition groups. Only the working condition domain reported significantly differences mean scores across the six chronic health condition groups. However, effect size of these differences was small. In fact, pair wise comparisons revealed that only participants with migraine scored higher in comparison with people with diabetes mellitus. 
TABLE 2. Employment Need Domains Scores for Total Sample and by Type of Health Condition

\begin{tabular}{|c|c|c|c|c|c|c|c|c|c|}
\hline $\begin{array}{l}\text { Employment Needs } \\
\text { Mean (SD) }\end{array}$ & $\begin{array}{l}\text { Total Sample } \\
(n=686)\end{array}$ & $\begin{array}{l}\text { Migraine } \\
(n=137)\end{array}$ & $\begin{array}{c}\text { Back and } \\
\text { Neck Pain } \\
(\boldsymbol{n}=95)\end{array}$ & $\begin{array}{l}\text { COPD }^{*} \\
(n=86)\end{array}$ & $\begin{array}{l}\text { Depression } \\
(n=122)\end{array}$ & $\begin{array}{l}\text { Diabetes } \\
\text { Mellitus } \\
(n=191)\end{array}$ & $\begin{array}{c}\text { Ischemic } \\
\text { Heart Disease } \\
\quad(n=55)\end{array}$ & $\mathbf{F}^{\dagger}(\boldsymbol{P})$ & $\mathbf{E S}^{\ddagger}$ \\
\hline Physical adaptations & $78.55(19.22)$ & 82.07 (18.86) & 76.19 (19.76) & 73.82 (19.94) & 79.04 (18.63) & $79.36(18.59)$ & $77.76(20.31)$ & $1.95(P=0.084)$ & 0.09 \\
\hline Working conditions & $77.84(17.50)$ & $81.49(15.61)$ & 75.91 (19.94) & $75.69(16.40)$ & $80.35(15.86)$ & $74.70(18.43)$ & 75.97 (17.15) & $3.28(P=0.006) \S$ & 0.13 \\
\hline Legislative needs & $76.83(23.61)$ & $73.07(25.44)$ & $78.67(22.97)$ & 78.07 (19.39) & $78.27(25.09)$ & $76.90(23.69)$ & $77.28(21.77)$ & $0.86(P=0.51)$ & $<0.01$ \\
\hline $\begin{array}{l}\text { Medical and health } \\
\text { care needs }\end{array}$ & 76.64 (18.87) & 77.27 (15.88) & 73.68 (22.09) & $75.07(17.35)$ & $79.12(19.76)$ & 77.49 (19.89) & $73.55(14.72)$ & $1.21(P=0.30)$ & 0.04 \\
\hline $\begin{array}{l}\text { Personal education } \\
\text { and training }\end{array}$ & $78.30(20.33)$ & 77.25 (20.19) & $75.71(23.02)$ & 77.79 (17.56) & 79.79 (21.19) & 80.91 (19.08) & 73.92 (21.13) & $1.39(P=0.23)$ & 0.06 \\
\hline $\begin{array}{c}\text { Increasing awareness } \\
\text { in the workplace }\end{array}$ & $78.71(20.89)$ & $77.70(21.24)$ & $79.80(18.72)$ & $76.56(17.92)$ & $79.84(21.81)$ & $79.80(22.75)$ & $75.41(18.22)$ & $0.64(P=0.67)$ & $<0.01$ \\
\hline
\end{tabular}

\section{Employment Needs Categories by Type of Welfare System}

With the exception of the Working Conditions domain, all the employment need domains were differently perceived in the four welfare system groups (Table 3). In general, participants from Continental and Mediterranean countries perceived more favorably employment needs related to Personal Education \& Training, Raising Awareness in the Workplace and Health and Medical care in comparison with participants from Scandinavian system (Table 3). The Raising Awareness in the Workplace domain also obtained higher scores in Continental (mean diff $=11.35$; $P \leq 0.001$ ) and Mediterranean countries (mean diff $=11.53$; $P \leq 0.001)$ in comparison with Postcommunist countries. Effect sizes of these differences were small-to-moderate. The legislative needs domain was more helpful for Postcommunist group in comparison with participants from Scandinavian (mean diff $=12.51 ; P \leq 0.001$ ) and from Mediterranean models (mean $\operatorname{diff}=8.28 ; P=0.029)$. However, effect sizes of differences were small.

\section{Employment Needs Categories by Main Type of Occupation (Only Employed)}

Employment needs mean sores for each occupational group are showed in Table 4. No significant differences were found for type of employment needs among the different ISCO occupation groups.

\section{DISCUSSION}

The present study has reported relevant findings and constitutes a first step towards the creation of meaningful strategies to promote employability of people with chronic health conditions as it allowed us to directly collect opinions amongst the real users of employment strategies.

Our study has collected a list of specific employment needs perceived as very favorable or very unfavorable by people with six different chronic health condition groups in nine different countries which represent four types of social welfare systems. In general, participants of our study scored very favorably to have a flexible work routine, which is line with previous studies conducted at country level. ${ }^{14,15}$ In addition, people rated very positively the fact of securing time to attend medical appointments, which to our knowledge had not been reported by previous literature.

On the other hand, this study also showed that people with chronic health conditions scored very unfavorably the fact of being laid-off should their productivity decreased because of their chronic health condition issues. This is a challenging situation if we consider that one the reasons that employers have frequently reported for not hiring people with health problems is the fear of legal liability. ${ }^{31}$ However, existing evidence suggests that hiring people with health

TABLE 3. Employment Need Domains Scores by Type Of Welfare System

\begin{tabular}{|c|c|c|c|c|c|c|c|}
\hline $\begin{array}{l}\text { Employment Needs } \\
\text { Mean (SD) }\end{array}$ & $\begin{array}{l}\text { Scandinavian } \\
\quad(n=144)\end{array}$ & $\begin{array}{l}\text { Continental } \\
(n=184)\end{array}$ & $\begin{array}{l}\text { Mediterranean } \\
\quad(n=270)\end{array}$ & $\begin{array}{l}\text { Postcommunist } \\
\quad(n=87)\end{array}$ & $\boldsymbol{F}^{*}(\boldsymbol{P})$ & $\mathbf{E S}^{\dagger}$ & $\begin{array}{c}\text { Bonferroni } \\
\text { Comparisons }^{\ddagger}\end{array}$ \\
\hline Physical adaptations & $78.93(20.75)$ & $74.05(22.27)$ & $82.04(18.05)$ & 76.19 (11.89) & $5.85(\leq 0.001)$ & 0.16 & MED > CONT \\
\hline Working conditions & $78.09(22.80)$ & 78.99 (16.70) & $76.32(17.28)$ & $76.64(9.15)$ & $0.88(0.45)$ & - & - \\
\hline Legislative needs & $71.48(28.45)$ & $79.10(24.48)$ & $75.71(22.87)$ & $83.99(10.65)$ & $5.61(\leq 0.001)$ & 0.15 & $\begin{array}{c}\text { POST }>\text { SCAN and MED } \\
\text { CONT }>\text { SCAN }\end{array}$ \\
\hline $\begin{array}{l}\text { Medical and health } \\
\text { care needs }\end{array}$ & $68.62(24.74)$ & $78.09(15.88)$ & $80.34(17.39)$ & $72.65(11.73)$ & $11.36(\leq 0.001)$ & 0.23 & $\begin{array}{c}\mathrm{CONT} \text { and } \mathrm{MED}>\mathrm{SCAN} \\
\mathrm{MED}>\mathrm{POST}\end{array}$ \\
\hline $\begin{array}{l}\text { Personal education } \\
\text { and training }\end{array}$ & $70.02(25.63)$ & 80.37 (22.29) & $81.66(16.98)$ & $75.51(14.51)$ & $9.21(\leq 0.001)$ & 0.21 & $\mathrm{CONT}$ and $\mathrm{MED}>\mathrm{SCAN}$ \\
\hline $\begin{array}{l}\text { Increasing awareness in } \\
\text { the workplace }\end{array}$ & $70.54(28.40)$ & $81.89(17.50)$ & $82.07(20.58)$ & $72.19(11.95)$ & $11.88(\leq 0.001)$ & 0.23 & $\begin{array}{l}\mathrm{CONT} \text { and } \mathrm{MED}>\mathrm{SCAN} \\
\mathrm{CONT} \text { and } \mathrm{MED}>\mathrm{POST}\end{array}$ \\
\hline
\end{tabular}


TABLE 4. Employment Need Domains Scores by Type of Occupation (Only for Employed Participants)

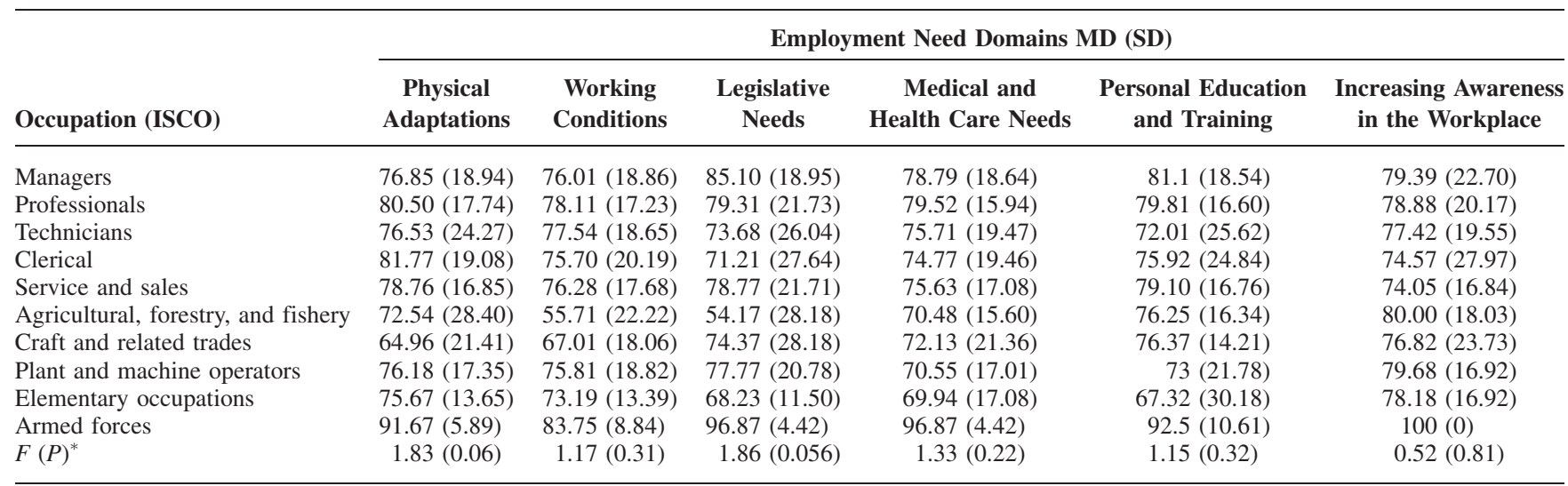

${ }^{*} \mathrm{~F}$ : ANOVA.

problems is actually a win-win action for employer and employees. ${ }^{32}$ Some authors argue these actions should be additionally accompanied by the availability of employment services that incorporate the employer interests and do not only appeal "charitable" causes. $^{33}$

At global level, this study has also underlined that people with chronic health conditions perceived actions aimed at raising awareness of chronic health conditions in the workplace as the area more favorable. Lack of understanding of employers and of colleagues has been frequently reported as one of the problems that people with chronic health conditions usually experience in the workplace. ${ }^{14,15}$ Raising awareness of chronic health conditions in the workplace might prevent episodes of stigma and discrimination that some workers experience as they disclose they have a health condition at the workplace. ${ }^{34}$ Previous studies have suggested that employees are more willing to receive health-related knowledge if there is a high coworker support. ${ }^{35}$ Interventions addressed to raise the awareness of chronic health conditions in the workplace should probably include actions at individual and organizational levels.

In addition, the present work has also conducted comparisons of employment needs across different health condition groups. The lack of differences found across the health condition groups suggest that there might be a common experience of suffering from a chronic health condition in the workplace which is beyond the specific type of chronic health condition. This result is line with the idea that it could be possible to launch common strategies, targeting factors that are relevant across different chronic health condition groups. The lack of differences between chronic health conditions also suggests that it might be worth trying to transfer certain interventions that have proven effective on one chronic health condition to others. For example, workplace ergonomic interventions, very frequently applied in people with musculoskeletal problems $^{36}$ might be also beneficial for people with migraine, whereas individual placement support frequently used in mental conditions $^{37}$ might be also suitable for people with diabetes or chronic obstructive pulmonary disease.

To our knowledge this is the first study that has compared the type of employment needs experienced by people with chronic health conditions in different social welfare systems. The results indicated that the perception of employment needs varied considerably from one welfare system to another. Several reasons might account for these differences. The first explanation is related to the fact that some welfare systems do not cover the employment needs of people with chronic health conditions. ${ }^{20}$ It is possible that the employment needs reported as more favorably are those ones that are perceived as frustrated or unmet. ${ }^{38}$ Post-communist welfare model is defined by a lower development of employment policies and systems in comparison with Continental or Scandinavian countries. ${ }^{39}$ This might explain why people from Postcommunist countries perceived needs related to legislation as very favorably. Another explanation for these differences is given by the socialconstructivist perspectives. ${ }^{40}$ According to these theories, people's opinions are heavily influenced by the amount of demands, obstacles, and reinforcements experienced within each culture. For example, continental countries are characterized by having high-quality vocational training and education systems. ${ }^{41}$ This might explain why the participants from the continental model scored very favorably the needs related to education and training. Therefore, our study underlines that the type of employment needs perceived might depend on what is considered as unmet but also on what is considered valuable to a society. Although some specific occupations have been related to higher incidence of diseases, ${ }^{42}$ the findings of the present study suggest that type of occupation was not related to experience different employment needs. It is possible that corporate cultures are related to employment needs rather than type of occupation. ${ }^{43}$ Nonetheless, further studies are necessary since there were some occupations such as armed forces and agricultural, forestry and fishery workers, that were underrepresented in the sample.

The main strengths of the present study were the application of a systematic process of the relevant employment needs to evaluate, the harmonized process of data collection in a range of different European countries and the selection of the chronic health conditions that are associated with higher disability in the European regions. However, there are also some weaknesses which should be considered to interpret our study results. One limitation is the fact that we only collected opinions from individuals pertaining to patient associations and with a literacy and technological level that allowed them to answer the online questionnaire. In addition, diagnoses were self-reported and could be not be confirmed by expert's information. Moreover, information on the participant's workplace characteristics was not collected. Specific workplace conditions and their relationship with employment needs in people with chronic health problems should be further analyzed. Finally, we acknowledge that although the countries comprising the welfare system groups share cultural and political characteristics there are also probably differences within these welfare system groups that have not been analyzed.

In spite these limitations, the present work has provided a wide list of main factors that were considered as very favorable by 
people chronic health condition for their fully (re)integration in the workplace. Our results suggest that there is probably a common experience of living with a chronic health condition beyond the specific type of health condition suffered from. Our study also suggests that employment needs are strongly related to the type of social welfare system. The characteristics of each European welfare system should be considered to enhance the participation of people with chronic health conditions in the European workforce.

\section{ACKNOWLEDGMENTS}

The authors thank the participation of the associations, NGOs, and organizations which kindly distribute the study questionnaire among people with chronic health conditions as well to the study participants who dedicated time to participate in the study.

\section{REFERENCES}

1. World Health Organization. Health topics. Noncommunicable diseases; 2017. Available at: http://www.who.int/topics/noncommunicable_diseases/ en/. Accessed January 17, 2018.

2. Suzman R, Beard JR, Boerma T, Chatterji S. Health in an ageing worldwhat do we know? Lancet. 2015;385:484-486.

3. Milner A, Krnjacki L, Butterworth P, Kavanagh A, LaMontagne AD. Does disability status modify the association between psychosocial job quality and mental health? A longitudinal fixed-effects analysis. Soc Sci Med. 2015;144:104-111.

4. Schuring M, Burdorf L, Kunst A, Mackenbach J. The effects of ill health on entering and maintaining paid employment: evidence in European countries. J Epidemiol Community Health. 2007;61:597-604.

5. Stewart JM. The impact of health status on the duration of unemployment spells and the implications for studies of the impact of unemployment on health status. J Health Econ. 2001;20:781-796.

6. Pinilla-Roncancio M. The reality of disability: multidimensional poverty of people with disabled and their families in Latin America. Disabil Health J. 2017; 11:398-404.

7. Curnock E, Leyland AH, Popham F. The impact on health of employment and welfare transitions for those receiving out-of-work disability benefits in the UK. Soc Sci Med. 2016;162:1-10.

8. Schur L, Nishii L, Adya M, Kruse D, Bruyère SM, Blanck P. Accommodating employees with and without disabilities. Hum Resour Manage. 2014;53: $593-621$.

9. Ihara E. In: Institute HP, editor. Workers Affected by Chronic Conditions: How Can Workplace Policies and Programs Help?. Washington, DC: Health Policy Institute at Georgetown University; 2004.

10. Xiong C, Martin T, Sravanapudi A, Colantonio A, Mollayeva T. Factor associated with return to work in men and women with work-related traumatic brain injury. Disabil Health J. 2016;9:439-448.

11. Rosenheck R, Leslie D, Keefe R, et al. Barriers to employment for people with schizophrenia. Am J Psychiatry. 2006;163:411-417.

12. Ruston A, Smith A, Fernando B. Diabetes in the workplace-diabetic's perceptions and experiences of managing their disease at work: a qualitative study. BMC Public Health. 2013;13:386.

13. van Egmond M, Duijts SFA, Loyen A, Vermeulen SJ, van der Beek AJ, Anema JR. Barriers and facilitators for return to work in cancer survivors with job loss experience: a focus group study. Eur J Cancer Care. 2017;26:e12420.

14. Varekamp I, Van Dijk F. Workplace problems and solutions for employees with chronic diseases. Occup Med. 2010;60:287-293.

15. Vooijs M, Leensen MC, Hoving JL, Wind H, Frings-Dresen MH. Perspectives of people with a chronic disease on participating in work: a focus group study. J Occup Rehabil. 2017;27:593-600.

16. European Association of Service Providers for Persons with Disabilities (EASPD). Social welfare systems across Europe. 2016. Available at http:// www.easpd.eu/sites/default/files/sites/default/files/SensAge/d4-social_welfare_systems_across_europe.pdf. Accessed July 17, 2018.

17. Sapir A. Globalization and the reform of European social models. JCMS 2006;44:369-390.

18. Dahl E. Disability and employment: sustainability of 'the Nordic model' Eur J Public Health. 2010;20:370-371.
19. Eikemo TA, Bambra C, Joyce K, Dahl E. Welfare state regimes and incomerelated health inequalities: a comparison of 23 European countries. Eur J Public Health. 2008; 18:593-599.

20. Scaratti C, Leonardi M, Silvaggi F, et al. Mapping European Welfare Models state of the art of strategies for professional integration and reintegration of persons with chronic diseases. Int J Environ Res and Public Health. 2018;15:781.

21. Europa Caritas. The Future of the Welfare State: A Comparative Study in EUcountries. In: Lambertus-Verlag, ed. Available at: https://wwwcaritaseu/sites/ default/files/publication_caritas_europa_-_future_welfare_state_0pdf. Breisgau, Germany; 2012.

22. Mladenov T. Postsocialist disability matrix. Scand J Disabil Res. 2017; 19:104-117.

23. European Commission. PArticipation To Healthy Workplaces And inclusive Strategies in the Work Sector. PATHWAYS Project. European Union's Health Programme (2014-2020) Grant agreement n. 663474. 2015.

24. World Health Organization. International Classification of Functioning, Disability and Health (ICF). Geneva, Switzerland: World Health Organization; 2001.

25. Institute for Health Metrics and Evaluation. Global Burden of Disease Study 2015 (GBD 2015) Incidence, Prevalence, and Years Lived with Disability 1990-2015. Data Visualization. USA: University of Washington 2015.

26. World Health Organization. ICD-10: International Statistical Classification of Diseases and Related Health Problems: Tenth Revision. Geneva: World Health Organization; 2004.

27. International Labour Organization. 88: International Standard Classification of Occupations (ISCO). Geneva, Switzerland: International Labor Organization; 1990.

28. Cronbach LJ. Coefficient alpha and the internal structure of tests. Psychometrika. 1951;16:297-334.

29. StataCorp LLC. Stata Statistical Software: Release 14. In: College Station TSL, ed. College Station, TX; 2015.

30. Muthén LK, Muthén, BO. Mplus User's Guide. 6th ed. In: Muthén. M, ed. Los Angeles, CA; 1998-2011.

31. Kaye HS, Jans LH, Jones EC. Why don't employers hire and retain workers with disabilities? J Occup Rehabil. 2011;21:526-536.

32. Lindsay S, Cagliostro E, Albarico M, Mortaji N, Karon L. A systematic review of the benefits of hiring people with disabilities. J Occup Rehabil. 2018;1-22.

33. Luecking RG. Emerging employer views of people with disabilities and the future of job development. J Vocat Rehabil. 2008;29:3-13.

34. Toth KE, Dewa CS. Employee decision-making about disclosure of a mental disorder at work. J Occup Rehabil. 2014;24:732-746.

35. Meng L, Galyardt AK, Robinson KT, et al. Factors associated with interest in worksite health-related discussions/events among employed adults with chronic conditions. J Occup Environ Med. 2017;59:e145-e149.

36. Arnetz BB, Sjögren B, Rydéhn B, Meisel R. Early workplace intervention for employees with musculoskeletal-related absenteeism: a prospective controlled intervention study. J Occup Environ Med. 2003;45: 499-506.

37. Whitworth A. The economic case for well-considered investment in healthrelated employment support: Costs and savings of alternative modified Individual and Placement Support (IPS) models. Disabil Health J. 2018; S1936-6574(18)30040-2. doi:10.1016/j.dhjo.2018.02.004

38. Sheldon KM, Gunz A. Psychological needs as basic motives, not just experiential requirements. J Pers. 2009;77:1467-1492.

39. Bloom D, Michalopoulos C. How Welfare and Work Policies Affect Employment and Income: A Synthesis of Research. New York: Manpower Demonstration Research Corporation; 2001.

40. Buttle F. The social construction of needs. Psychol Market. 1989;6:197-210.

41. Hemerijck A. The self-transformation of the European social model (s). Int Pol Gesellschaft. 2002;39-67.

42. Corral AD, J. Isusi, I. Employment Opportunities for People With Chronic Diseases. Loughlinstown: European Foundation for the Improvement of Living and Working Conditions European Foundation for the Improvement of Living and Working Conditions (Eurofound); 2014.

43. Schur L, Kruse D, Blasi J, Blanck P. Is disability disabling in all workplaces? Workplace disparities and corporate culture. Ind Relat A J Econ Soc. 2009;48:381-410. 